\title{
ANOSMIA AND AGEUSIA IN PATIENTS WITH COVID-19
}

\author{
Tahir Ghulam Abbas, Atif Hafeez Siddiqui, Syed Hasan Abbas Zaidi, Danish-Ur-Rahim, Irfan Ahmed Shaikh, Arfat Bashir Soomro*, \\ Muhammad Shuja Farrukh, Jahanzeb Kamal** \\ Dow University of Health Sciences, Karachi Pakistan, *Liaquat College of Medicine \& Dentistry, Karachi Pakistan, **King's College London, London England
}

\begin{abstract}
Objective: To evaluate the prevalence and diagnostic significance of anosmia and ageusia among COVID-19 positive patients of Karachi, Pakistan.

Study Design: Cross-sectional study.

Place and Duration of Study: Dr Ruth K. M. Pfau Civil Hospital, (Dow University of Health Sciences), Karachi Pakistan, from Jan 2021 to Feb 2021.

Methodology: The data were collected prospectively from 265 COVID-19 positive patients. Some patients were interviewed over the telephone, while for patient's ease, an online Google form was also formed, facilitating the online data collection. The patient's demographics, comorbidities, allergies, and COVID-19 associated characteristics were inquired. The statistical analysis was performed on SPSS version 23.

Results: The observed frequency of anosmia and ageusia in COVID-19 patients was $49.1 \%$ \& $43.8 \%$ respectively. The median time to recovery was 8-8.5 days (median) for both symptoms. We found no significant difference for gender, BMI, marital status, residential area, comorbidities and reason for long-standing breathing difficulties between patients with or without both anosmia and ageusia $(p>0.05)$. Furthermore, most of the cigarette smokers reported none of the two symptoms (anosmia and ageusia), $24 \%$ and $25.2 \%$ of COVID-19 positive cases with smoking history were presented without anosmia and ageusia, respectively $(p<0.05)$.

Conclusion: Loss of sense of smell and taste was reported in almost half of the studied population infected by the SARS-CoV-2 virus. Therefore, screening for anosmia and ageusia must be considered while COVID-19 suspicion as an important diagnostic clue.
\end{abstract}

Keywords: Anosmia, Ageusia, COVID-19, Smell, Taste.

How to Cite This Article: Abbas TG, Siddiqui AH, Zaidi SHA, Rahim DU, Shaikh IA, Soomro AB, Farrukh MS, Kamal J. Anosmia and Ageusia in Patients with COVID-19. Pak Armed Forces Med J 2021; 71 (Suppl-3): S512-516 Doi: https://doi.org/10.51253/pafmj.v1i1.7934

This is an Open Access article distributed under the terms of the Creative Commons Attribution License (https://creativecommons.org/licenses/by-nc/4.0/), which permits unrestricted use, distribution, and reproduction in any medium, provided the original work is properly cited.

\section{INTRODUCTION}

The epidemic of COVID-19 caused by the severe acute respiratory syndrome coronavirus 2 (SARS-CoV2) that emerged from East Asia, has rapidly spread to the rest of the world, causing a spectrum of symptoms, is so far responsible for $>3.5$ million deaths worldwide, and approximately 20,000 deaths in Pakistan. ${ }^{1}$ The rapid viral transmission has enabled researchers to obtain large amounts of clinical data as the traits, symptoms and disease durations varied across the globe and surprisingly contrasting compared to that reported initially in China. ${ }^{2}$

The research and scientific literature also evolved with the disease progression; initially most frequently reported symptoms among inpatient COVID-19 cases were fever, cough, dyspnea, sputum production, myalgia, arthralgia, headache, diarrhea, rhinorrhea, and sore throat. Later, a number of studies from various geographical locations reported a significant gustatory and olfactory loss among COVID-19 patients. ${ }^{2}$ Vaira et

Correspondence: Dr Atif Hafeez Siddiqui, Associate Professor, ENT Unit-1, Dow University of Health Sciences, Karachi Pakistan $a l$, from Italyconducted a study including 72 COVID-19 positive patients; they reported olfactory and gustatory alterations in $>70 \%$ of the studied patients. ${ }^{3}$ A study from China with 214 COVID-19 patients reported anosmia in only $5.1 \%$ patients and ageusia in $5.6 \%$ of patients. ${ }^{4}$ In a meta-analysis including 19 studies, Tong et al, documented anosmia and ageusia as the significant COVID-19 symptoms, the reported frequency of anosmia and ageusia as per the reviewed literature was more than $50 \%$ and $>40 \%$, respectively. $5,12,13$

The otolaryngological importance of anosmia and ageusia in COVID-19 could be explained by the direct damage of the olfactory and gustatory receptors and the subsequent loss of the two senses.6,7,14-8 The effects of anosmia can be diverse and impactful; affected patients frequently reported decreased capability to identify personal hazards, such as fire, gas, obnoxious chemicals or spoiled food. At the same time, ageusia compromises the patient's quality of life, as it is associated with loss of appetite and reduction in weight.

Although a number of studies analyzing the symptomatic profile of the COVID-19 patients have 
been carried out, there is very limited data reported from the specific studied region. Therefore, this study was designed for better understanding and management of the infection. We aimed to evaluate theprevalence and diagnostic significance of anosmia and ageusia among COVID-19 positive patients of Karachi, Pakistan.

\section{METHODOLOGY}

This cross-sectional study was conducted at Dr. Ruth K. M. Pfau Civil Hospital, Karachi (Dow University of Health Sciences), from January 2021 to February 2021, including a total of 265 COVID-19 positive patients selected via non-probability convenience sampling technique. The sample size was calculated using the World Health Organization (WHO)calculator for Health Studies, considering 95\% confidence level and $5 \%$ margin of error. As cited in the literature for sample size calculation, the prevalence of both anosmia and ageusia was $19 \% .8$

Inclusion Criteria: Both male and female patients, aged 18 years or above, were includedafter obtaining written informed consent.

Exclusion Criteria: Individuals with pre-existing pathological or traumatic conditions leading to loss of sense of smell and/or taste were excluded.

Apre-designed proforma focusing on the study objectives was used for data collection. The questionnaire was pre-tested through a pilot study involving 30 patients. Some patients were interviewed over the telephone, while for patient's ease, an online Google form was also formed, facilitating the online data collection. The data regarding demographics, comorbidities, allergies, symptoms, requirement of hospitalization, the requirement of oxygen support during the illness, onset of anosmia \& ageusia, and duration.

The statistical analysis was performed on SPSS23. Continuous variables were presented as mean \pm SD while frequencies and percentages were used to display categorical variables. A chi-square test was used to determine the association of patient characteristics (categorical variables) with anosmia and ageusia, and an independent $t$-test was used for continuous variables. A $p$-value of less than 0.05 was considered statistically significant.

The study was commenced after obtaining ethical approval from the Institutional Review Board (IRB) of Dow University of Health Sciences (DUHS) (Ref: IRB1867/DUHS/Approval/2021; Dated: Jan 30, 2021). All ethical guidelines and standard operating procedures (SOPs) were followed.

\section{RESULTS}

It was observed that out of 265 COVID-19 patients, anosmia was reported by $49.1 \%$, of which $14.6 \%$ reported that it started on day $1,55.4 \%$ reported it on day $2-4$, and $30 \%$ reported it on day $5 \&$ above. The number of days [median (IQR)during which anosmia subsided was 8.5 (5.8-15) days. While, the mean duration of ageusia was 8 (6-15) days, after which the symptom subsided. It was reported by $43.8 \%$ of the enrolled patients, of which $10.3 \%$ reported that it started on day 1 , on day $2-4$ in $58.8 \%$ and $30.9 \%$ reported it on day $5 \&$ above.

Table-I shows the characteristics of COVID-19 patients with and without anosmia and ageusia. There was no significant difference with respect to gender, BMI, marital status, residential area, comorbidities and reason for long-standing breathing difficulties between patients with or without both anosmia and ageusia $(p>0.05)$. While the mean age of the patients with anosmia was comparatively low than those without anosmia, i.e. $34.3 \pm 12.9$ years vs. $38.43 \pm 13.84$ years $(p=$ 0.012). Dust allergy was significantly higher among COVID-19 patients with anosmia $(p=0.013)$. Furthermore, most of the cigarette smokers reported none of the two symptoms (anosmia and ageusia), 24\% and $25.2 \%$ of COVID-19 positive cases with smoking history were presented without anosmia and ageusia, respectively $(p<0.05)$.

The stratification of COVID-19 characteristics for anosmia and ageusia is displayed in Table-II. It was observed that there was no significant difference in the sources of infection contraction among the patients with or without anosmia and ageusia. While the presence of other symptoms when tested positive for COVID-19 was significant among those with anosmia or ageusia $(p<0.001)$. Most of the patients with either anosmia or ageusia reported the symptomatic onset before the PCR test. Surprisingly, the hospitalization and oxygen requirement was higher among the patients without any of the two symptoms.

\section{DISCUSSION}

As known, the best way to prevent and slow down viral transmission is to be well informed. With the disease progression, the presence of chemosensory dysfunction became more evident among COVID-19 patients. ${ }^{3,4,7}$ It is now recommended that the suspected COVID-19 must be inquired regarding the gustatory or 
olfactory loss together with other COVID-related symptoms. sia, but these symptoms were comparatively more frequent among males than females (Table-II). A similar

\begin{tabular}{|c|c|c|c|c|c|c|c|}
\hline \multicolumn{2}{|l|}{ Variables } & $\begin{array}{c}\text { With } \\
\text { Anosmia }\end{array}$ & $\begin{array}{l}\text { Without } \\
\text { Anosmia }\end{array}$ & $p$-value & $\begin{array}{c}\text { With } \\
\text { Ageusia }\end{array}$ & $\begin{array}{l}\text { Without } \\
\text { Ageusia }\end{array}$ & $p$-value \\
\hline \multicolumn{2}{|c|}{ Age (years); Mean \pm SD } & $34.3 \pm 12.9$ & $38.4 \pm 13.8$ & $0.012^{*}$ & $38.4 \pm 13.8$ & $35.0 \pm 13.0$ & 0.148 \\
\hline \multirow{3}{*}{$\begin{array}{l}\text { Age group } \\
\text { (years) }\end{array}$} & $18-45$ & $108(83.1)$ & 99(73.3) & \multirow{3}{*}{0.131} & $94(81)$ & $113(75.8)$ & \multirow{3}{*}{0.282} \\
\hline & $46-60$ & $17(13.1)$ & $25(18.5)$ & & $18(15.5)$ & $24(16.1)$ & \\
\hline & $>60$ & $5(3.8)$ & $11(8.1)$ & & $4(3.4)$ & $12(8.1)$ & \\
\hline \multirow{2}{*}{ Gender } & Male & $73(56.2)$ & $73(54.1)$ & \multirow{2}{*}{0.734} & $68(58.6)$ & $78(52.3)$ & \multirow{2}{*}{0.309} \\
\hline & Female & $57(43.8)$ & $62(45.9)$ & & $48(41.1)$ & $71(47.7)$ & \\
\hline \multicolumn{2}{|c|}{ BMI $\left(\mathrm{kg} / \mathrm{m}^{2}\right) ;$ Mean $\pm \mathrm{SD}$} & $25.8 \pm 5.1$ & $25.5 \pm 4.6$ & 0.658 & $25.5 \pm 4.6$ & $25.3 \pm 3.6$ & 0.202 \\
\hline \multirow{4}{*}{ BMI Groups } & $<18$ & $6(4.6)$ & $5(3.7)$ & \multirow{4}{*}{0.915} & $5(4.3)$ & $6(4.0)$ & \multirow{4}{*}{0.210} \\
\hline & $18-24.99$ & $44(33.8)$ & $50(37.0)$ & & $33(28.4)$ & $61(40.9)$ & \\
\hline & $25-29.99$ & $60(46.2)$ & $62(45.9)$ & & $59(50.9)$ & $63(42.3)$ & \\
\hline & $\geq 30$ & $20(15.4)$ & $18(13.3)$ & & $19(16.4)$ & $19(12.8)$ & \\
\hline \multirow{2}{*}{ Marital Status } & Single & $36(32.4)$ & $33(27.3)$ & \multirow{2}{*}{0.39} & $28(28.9)$ & $41(30.4)$ & \multirow{2}{*}{0.805} \\
\hline & Married & $75(67.6)$ & $88(72.7)$ & & $69(71.1)$ & $94(69.6)$ & \\
\hline \multirow{7}{*}{ Occupation } & Student & $10(7.7)$ & $5(3.7)$ & \multirow{7}{*}{0.009} & $8(6.9)$ & $7(4.7)$ & \multirow{7}{*}{0.142} \\
\hline & Employed & $40(30.8)$ & $47(34.8)$ & & $35(30.2)$ & $52(34.9)$ & \\
\hline & Unemployed & $3(2.3)$ & $8(5.9)$ & & $5(4.3)$ & $6(4.0)$ & \\
\hline & Business & $2(1.5)$ & $14(10.4)$ & & $2(1.7)$ & $14(9.4)$ & \\
\hline & Housewife & $15(11.5)$ & $19(14.1)$ & & $14(12.1)$ & $20(13.4)$ & \\
\hline & Healthcare Professional & $59(45.4)$ & $41(30.4)$ & & $51(44)$ & $49(32.9)$ & \\
\hline & Others & $1(0.8)$ & $1(0.7)$ & & $1(0.9)$ & $1(0.7)$ & \\
\hline \multirow{7}{*}{$\begin{array}{l}\text { Area of Living } \\
\text { in Karachi }\end{array}$} & Cantonment & $7(5.4)$ & $10(7.4)$ & \multirow{7}{*}{0.389} & $7(6.0)$ & $10(6.7)$ & \multirow{7}{*}{0.873} \\
\hline & Central & $36(27.7)$ & $41(30.4)$ & & $32(27.6)$ & $45(30.2)$ & \\
\hline & East & $40(30.8)$ & $35(25.9)$ & & $35(30.2)$ & $40(26.8)$ & \\
\hline & West & $10(7.7)$ & $15(11.1)$ & & $12(10.3)$ & $13(8.7)$ & \\
\hline & South & $27(20.8)$ & $17(12.6)$ & & $21(18.1)$ & $23(15.4)$ & \\
\hline & Malir & $7(5.4)$ & $13(9.6)$ & & $6(5.2)$ & $14(9.4)$ & \\
\hline & Korangi & $3(2.3)$ & $4(3.0)$ & & $3(2.6)$ & $4(2.7)$ & \\
\hline \multicolumn{2}{|c|}{ Cigarette Smoker } & $13(11.7)$ & $29(24.0)$ & 0.015 & $8(8.2)$ & $34(25.2)$ & 0.001 \\
\hline \multirow{5}{*}{ Comorbidity } & Diabetes & $12(9.2)$ & $14(10.4)$ & 0.755 & $10(8.6)$ & $16(10.7)$ & 0.565 \\
\hline & Hypertension & $12(9.2)$ & $16(11.9)$ & 0.488 & $9(7.8)$ & $19(12.8)$ & 0.190 \\
\hline & Asthma & $6(4.6)$ & $8(5.9)$ & 0.634 & $4(3.4)$ & $10(6.7)$ & 0.239 \\
\hline & Heart Disease & $4(3.1)$ & $8(5.9)$ & 0.265 & $4(3.4)$ & $8(5.4)$ & 0.456 \\
\hline & Others & $5(3.8)$ & $4(3.0)$ & 0.692 & $3(2.6)$ & $6(4.0)$ & 0.521 \\
\hline \multirow{5}{*}{ Allergy } & Dust allergy & $48(36.9)$ & $31(23.0)$ & $0.013^{*}$ & $37(31.9)$ & $42(28.2)$ & 0.513 \\
\hline & Smoke allergy & $15(11.5)$ & $17(12.6)$ & 0.792 & $14(12.1)$ & $18(12.1)$ & 0.998 \\
\hline & Insecticides allergy & $11(8.5)$ & $10(7.4)$ & 0.751 & $9(7.8)$ & $12(8.1)$ & 0.930 \\
\hline & Strong smell allergy & $20(15.4)$ & $17(12.6)$ & 0.512 & $17(14.7)$ & $20(13.4)$ & 0.774 \\
\hline & Others & $3(2.3)$ & $5(3.7)$ & 0.507 & $2(1.7)$ & $6(4.0)$ & 0.277 \\
\hline Reason for & Deviated Nasal Septum & $15(11.5)$ & $8(5.9)$ & & $9(7.8)$ & $14(9.4)$ & 0.407 \\
\hline long-standing & Nasal Polyps & $3(2.3)$ & $4(3.0)$ & 0310 & $1(0.9)$ & $6(4.0)$ & \\
\hline difficulty in & Both & $4(3.1)$ & $2(1.5)$ & 0.310 & $3(2.6)$ & $3(2.0)$ & \\
\hline breathing & None & $108(83.1)$ & $121(89.6)$ & & $103(88.8)$ & $126(84.6)$ & \\
\hline
\end{tabular}

The enrolled patients were prospectively followed for symptom duration and cessation of anosmia and ageusia. It was observed that more than $40 \%$ of the enrolled patients had anosmia and ageusia (Table-III). There were no significant gender-based differences between patients with and without anosmia and ageu-
Korean study on 3,191 patients observed anosmia among $15.3 \%$ and ageusia in $15.7 \%$ of patients, with a significant prevalence among females. ${ }^{9}$ A local study from Swat reported that out of 100 COVID-19 patients, $43.75 \%$ had anosmia, and $31.25 \%$ had ageusia. ${ }^{10}$ 
Table-II: COVID-19 characteristics among patients with or without olfactory/gustatory loss.

\begin{tabular}{|c|c|c|c|c|c|c|c|}
\hline \multicolumn{2}{|l|}{ Variables } & $\begin{array}{c}\text { With } \\
\text { Anosmia }\end{array}$ & $\begin{array}{c}\text { Without } \\
\text { Anosmia }\end{array}$ & $p$-value & $\begin{array}{c}\text { With } \\
\text { Ageusia }\end{array}$ & $\begin{array}{l}\text { Without } \\
\text { Ageusia }\end{array}$ & $p$-value \\
\hline \multirow{4}{*}{$\begin{array}{l}\text { Ways of } \\
\text { Infection } \\
\text { Contracted }\end{array}$} & $\begin{array}{l}\text { Contact with a COVID- } \\
19 \text { Infection }\end{array}$ & $66(50.8)$ & $62(45.9)$ & \multirow{4}{*}{0.673} & $64(55.2)$ & $64(43.0)$ & \multirow{4}{*}{0.076} \\
\hline & Travel History & $5(3.8)$ & $8(5.9)$ & & $2(1.7)$ & $11(7.4)$ & \\
\hline & Other & $11(8.5)$ & $9(6.7)$ & & $8(6.9)$ & $12(8.1)$ & \\
\hline & Unknown & $48(36.9)$ & $56(41.5)$ & & $42(36.2)$ & $62(41.6)$ & \\
\hline \multirow{10}{*}{$\begin{array}{l}\text { Symptoms } \\
\text { When Tested } \\
\text { Positive for } \\
\text { COVID-19 }\end{array}$} & Yes & $126(69.9)$ & $12(83.0)$ & \multirow{2}{*}{$<0.001^{*}$} & $113(97.4)$ & $125(83.9)$ & \multirow{2}{*}{$<0.001^{*}$} \\
\hline & No & $4(3.1)$ & $23(17.0)$ & & $3(2.6)$ & $24(16.1)$ & \\
\hline & Fever & $99(76.2)$ & $84(62.2)$ & 0.014 & $93(80.2)$ & $90(60.4)$ & 0.001 \\
\hline & Dry Cough & $54(41.5)$ & $51(37.8)$ & 0.532 & $54(46.6)$ & $51(34.2)$ & 0.042 \\
\hline & Sore Throat & $58(44.6)$ & $49(36.3)$ & 0.168 & $54(46.6)$ & $53(35.6)$ & 0.171 \\
\hline & Nasal Congestion & $42(32.3)$ & $20(14.8)$ & 0.001 & $33(28.4)$ & $29(19.5)$ & 0.087 \\
\hline & Headache & $61(46.9)$ & $49(36.3)$ & 0.079 & $61(52.6)$ & $49(32.9)$ & 0.001 \\
\hline & Chills & 19(14.6) & $10(7.4)$ & 0.060 & $19(16.4)$ & $10(6.7)$ & 0.012 \\
\hline & Fatigue & $69(53.1)$ & $54(40.0)$ & $0.033^{*}$ & $62(53.4)$ & $61(40.9)$ & 0.043 \\
\hline & Diarrhea & $35(26.9)$ & $31(23.0)$ & 0.456 & $32(27.6)$ & $34(22.8)$ & 0.373 \\
\hline \multirow{4}{*}{$\begin{array}{l}\text { When } \\
\text { Symptoms } \\
\text { Started }\end{array}$} & Before PCR Test & $88(67.7)$ & $77(57.0)$ & \multirow{4}{*}{0.015} & $80(69)$ & $85(57.0)$ & \multirow{4}{*}{$<0.001^{*}$} \\
\hline & After PCR Test & $11(8.5)$ & $12(8.9)$ & & $10(8.6)$ & $13(8.7)$ & \\
\hline & Do not Know & 19(14.6) & $14(10.4)$ & & 19(16.4) & $14(9.4)$ & \\
\hline & Not Applicable & $12(9.2)$ & $32(23.7)$ & & $7(6.0)$ & $37(24.8)$ & \\
\hline \multirow{4}{*}{$\begin{array}{l}\text { Isolated or } \\
\text { Time Spent } \\
\text { During The } \\
\text { Illness }\end{array}$} & Home Isolation & $124(95.4)$ & $121(89.6)$ & \multirow{4}{*}{0.362} & 111(95.7) & $134(89.9)$ & \multirow{4}{*}{0.120} \\
\hline & Isolation Ward & $4(3.1)$ & $9(6.7)$ & & $5(4.3)$ & $8(5.4)$ & \\
\hline & High Dependency Unit & $1(0.8)$ & $2(1.5)$ & & - & $3(2.0)$ & \\
\hline & Intensive Care Unit & $1(0.8)$ & $3(2.2)$ & & - & $4(2.7)$ & \\
\hline \multicolumn{2}{|c|}{$\begin{array}{l}\text { Ever Required Oxygen Support During The } \\
\text { Illness }\end{array}$} & $3(2.7)$ & 13(10.7) & 0.016 & $4(4.1)$ & $12(8.9)$ & 0.158 \\
\hline \multicolumn{2}{|c|}{ Hospitalization Required } & $6(4.6)$ & $14(10.4)$ & 0.076 & $5(4.3)$ & $15(10.1)$ & 0.078 \\
\hline
\end{tabular}

The patients first reported anosmia on day 3 (median), and recovery time was 8.5 days (Table-III). In contrast, ageusia subsided in 8 days (Table-III). In contrast, AlAni and Acharya reported a mean recovery time from both anosmia and ageusia as $6.89 \pm 3.0$ days, with complete resolution among all patients within 312 days. ${ }^{11}$ Another study reports recovery from anosmia and ageusia in 7 days (median); they also reported that the young age group displayed a tendency for the symptomatic onset of anosmia and its persistence, ${ }^{9}$ which is also indicated in our study. Patients between 18-45 years of age frequently reported anosmia and ageusia compared to any other studied age group.

A notable finding of our study was that majority of the COVID-19 positive patients with anomia or ageusia did not require hospitalization and oxygen support. Of the 16 patients who required oxygen support, only 3 of them reported anosmia and four reported ageusia. Furthermore, out of 130 patients reporting anosmia, only six required hospitalizations and of 116 patients with ageusia, only five were hospitalized. These findings were not statistically significant but could be used for future research with larger and more diverse sample sizes. We found higher frequencies of these symptoms among less severe patients with mild to moderate COVID-19.

Table-III: COVID-19 patients with or without olfactory \& gustatory loss ( $\mathrm{n}=\mathbf{2 6 5})$.

\begin{tabular}{|c|c|c|}
\hline \multicolumn{2}{|l|}{ Variables } & n (\%) \\
\hline \multicolumn{2}{|c|}{ Loss of Sense of Smell (LSS) } & $130(49.1)$ \\
\hline \multicolumn{2}{|l|}{ Complete LSS (n=130) } & $94(72.3)$ \\
\hline \multirow{4}{*}{$\begin{array}{l}\text { LSS started on which } \\
\text { day of illness }\end{array}$} & median (IQR) & $3(2-5)$ \\
\hline & Day 1 & 19(14.6) \\
\hline & Day 2-4 & $72(55.4)$ \\
\hline & Day $5 \&$ above & $39(30)$ \\
\hline \multicolumn{2}{|c|}{ LSS subsided (days); median (IQR) } & $8.5(5.8-15)$ \\
\hline \multicolumn{2}{|c|}{ Loss of Sense of Taste (LST) } & $116(43.8)$ \\
\hline \multicolumn{2}{|c|}{ Complete LST $(\mathrm{n}=116)$} & $66(56.9)$ \\
\hline \multirow{4}{*}{ Element of LST $(n=97)$} & Sweet & $61(62.9)$ \\
\hline & Salt & $80(82.5)$ \\
\hline & Bitter & $61(62.9)$ \\
\hline & Sour & $60(61.9)$ \\
\hline \multirow{4}{*}{$\begin{array}{l}\text { LST started on which } \\
\text { day of illness, }(n=97)\end{array}$} & median (IQR) & $4(2-5)$ \\
\hline & Day 1 & $10(10.3)$ \\
\hline & Day 2-4 & $57(58.8)$ \\
\hline & Day $5 \&$ above & $30(30.9)$ \\
\hline \multicolumn{2}{|c|}{ LST subsided (days), (n=97); median (IQR) } & $8(6-15)$ \\
\hline
\end{tabular}


Lastly, studies report a significant recent travel history among COVID patients with anosmia and ageusia $(p<0.05) \cdot{ }^{10,11}$ However, contradictory to these outcomes, we observed no significant effect of travel history on the presence or absence of anosmia and ageusia among COVID-19 patients. Though the study provided sufficient knowledge on the two recognized symptoms of COVID-19, their onset, pattern, cessation, and contributing factors, certain limitations need to be addressed.

\section{ACKNOWLEDGEMENT}

The authors would like to acknowledge the Medical Affairs department of Getz Pharma for their technical support and assistance in the publication process.

\section{LIMITATION OF STUDY}

The research was based on a small sample size. We did not classify the disease based on severity, as the symptomatic profile also varies with disease severity.

\section{CONCLUSION}

Anosmia and ageusia were reported in almost half of the studied population infected by the SARS-CoV-2 virus. These symptoms being prevalent, can also help early detection of the infection and isolation of the individual to prevent the spreading of the infection.

\section{Conflict of Interest: None.}

\section{Authors' Contributions}

TGA: Substantial contributions to conception and design of study, acquisition, analysis and interpretation of data, and, drafting the article, AHS: Conception and design of study and revising the article critically for important intellectual content. Final approval of the version to be published, MSF \& DR \& IAS \& JK: Agreement to be accountable for all aspects of the work in ensuring that questions related to the accuracy or integrity of any part of the work are appropriately investigated and resolved, SHAZ \& ABS: Data collection \& proofreading.

\section{REFERENCES}

1. World Health Organization (WHO). Coronavirus disease (COVID-19) pandemic. [Updated: May 5th, 2021]. Available at: https://covid19.who.int/

2. Vaira LA, Salzano G, Fois AG, Piombino P, De Riu G. Potential pathogenesis of ageusia and anosmia in COVID-19 patients. Int Forum Allergy Rhinol 2020; 10(9): 1103-1104.
3. Vaira LA, Deiana G, Fois AG, Pirina P, Madeddu G, De Vito A, et al. Objective evaluation of anosmia and ageusia in COVID-19 patients: Single-center experience on 72 cases. Head Neck 2020; 42(6): 1252-1258.

4. Mao L, Wang M, Chen S, He Q, Chang J, Hong C, et al. Neurological manifestations of hospitalized patients with COVID-19 in Wuhan, China: a retrospective case series study. MedRxiv 2020, [Internet] Available at: https://www.medrxiv.org/content/ 10.1101/2020.02.22.20026500v1

5. Tong JY, Wong A, Zhu D, Fastenberg JH, Tham T. The prevalence of olfactory and gustatory dysfunction in COVID-19 patients: a systematic review and meta-analysis. Otolaryngol. Head Neck Surg 2020; 163(1): 3-11.

6. Vaira LA, Salzano G, Deiana G, De Riu G. Anosmia and ageusia: common findings in COVID-19 patients. The Laryngoscope. 2020; 130(7): 1787-1790.

7. MannanBaig A, Wasay M. Covid-19 infection; loss of taste, smell, and neurogenic respiratory failure. PJNS 2020; 15(1): 1-2.

8. Passarelli PC, Lopez MA, Bonaviri GM, Garcia-Godoy F, D' Addona A. Taste and smell as chemosensory dysfunctions in COVID-19 infection. Am J Dent 2020;33(3):135-137.

9. Lee Y, Min P. Prevalence and duration of acute loss of smell or taste in COVID-19 patients. J Korean Med Sci 2020; 35(18): 1-5.

10. Iqbal M, Khan SF, Khan S, Ahmad W. Prevalence of Anosmia \& Ageusia in confirmed COVID-19 patients at teaching hospitals of District Bannu and Swat, Pakistan. IJEHSR 2021: 9(2); 143-148.

11. Al-Ani RM, Acharya D. Prevalence of anosmia and ageusia in patients with COVID-19 at a primary health center, Doha, Qatar. Ind J Otolaryngol Head Neck Surg 2020; 2(1)1-7.

12. Khan S, Saleem Y, Aziz S. Psychological Response \& Perceived Risk Associated with Coronavirus Disease. APP 2020; 7(1): 9-18.

13. Gilani S, Roditi R, Naraghi M. COVID-19 and Anosmia in Tehran, Iran. Med Hypotheses 2020; 141: 109757

14. Menni C, Valdes A, Freydin MB, Ganesh S, Moustafa JE, Visconti A, Hysi P, Bowyer RC, Mangino M, Falchi M, Wolf J. Loss of smell and taste in combination with other symptoms is a strong predictor of COVID-19 infection. Med Rxiv 2020: 6-12.

15. Raid M. Al-Ani. Prevalence of Anosmia and Ageusia in Patients with COVID-19 at a Primary Health Center, Doha, Qatar. Indian J Otolaryngol Head Neck Surg 2020; 73(4): 1-7.

16. Kaye, R, Chang, CWD, Kazahaya, K, Brereton, J, Denneny, JC. COVID-19 anosmia reporting tool: initial findings. Otolaryngol Head Neck Surg 2020; 163(1): 132-4.

17. Speth MM, Singer-Cornelius T, Oberle M, Gengler I, Brockmeier SJ. Olfactory dysfunction and sinonasal symptomatology in COVID-19: prevalence, severity, timing, and associated characteristics. Otolaryngol Head Neck Surg 2020; 163(1): 114-20.

18. Paderno A, Mattavelli D, Rampinelli V, Grammatica A, Raffetti E, Tomasoni M, Gualtieri T, Taboni S, Zorzi S, Del Bon F, Lombardi D. Olfactory and gustatory outcomes in COVID-19: A prospective evaluation in non-hospitalized subjects. Otolaryngol Head Neck Surg 2020; 163(6): 1144-9. 